\title{
Can Preschoolers be Health Messengers to Promote Breast Health among Chinese Americans?
}

\author{
Angela C. Sun ${ }^{1}$, Eric R. Kessell ${ }^{2}$, Janice Y. Tsoh ${ }^{2}$, Joanne Chan ${ }^{1}$, and Joyce Chang ${ }^{1}$ \\ ${ }^{1}$ Chinese Community Health Resource Center \\ ${ }^{2}$ University of California, San Francisco
}

\begin{abstract}
Women's limited knowledge about breast cancer screening (BCS), combined with differences in Eastern and Western disease prevention concepts, may contribute to late-stage breast cancer diagnosis among minorities. Children can be conduits of knowledge transfer to adults. This pilot study tested the use of a culturally-tailored theatrical preschool performance in increasing Chinese American women's knowledge of BCS guidelines. Chinese preschool children relayed BCS guidelines through a culturally-tailored theatrical performance. Data were collected from 177 Chinese American women (84\% foreign-born) who completed pre- and post-performance surveys. Findings suggested that promoting BCS guidelines through a culturally-tailored preschool theatrical performance significantly increased participants' knowledge of the guidelines. Interventions involving young children as change agents to deliver simple health messages such as BCS guidelines are feasible and promising to increase knowledge and desired behavioral change within the target population. Further empirical investigations are warranted in larger randomized controlled trials.
\end{abstract}

(C) 2013 Californian Journal of Health Promotion. All rights reserved.

Keywords: Chinese, young children, breast cancer screening guidelines, performance, knowledge

\section{Introduction and Purpose}

Breast cancer screening rates are low among immigrants. According to American Cancer Society (2011), immigrants who resided in the U.S. for less than 10 years were less likely to have had a mammogram within the past year (26.8\%) or past two years (37.4\%) compared to those who were native-born $(51.6 \%$ and $67.1 \%$ respectively). . These low rates of breast cancer screening (BCS) among Chinese immigrants may be partially due to unfamiliarity with BCS guidelines (Chen, 2013) and differences in Eastern and Western disease prevention concepts (Liang, et al., 2009). BCS knowledge and practices are associated with high English proficiency (Chen, 2013; Ma, et al., 2012). Some traditional Chinese Americans believe that cancer is preventable or controllable by balancing internal energy levels, and do not understand the necessity of screening when asymptomatic (Liang, et al., 2009). Knowledge of BCS guidelines is essential because knowledge is one of the first steps that can lead to behavior change (Marx, Nedelmann, Haertle, Dieterich, \& Eicke, 2008). Research has suggested that children can be a conduit to transfer knowledge to their parents or other adults (Ayi et al., 2010). In a study of a schoolbased malaria control-education program in Ghana, children were educated by trained instructors about malaria transmission and prevention (Ayi, et al., 2010). The children then served as health messengers and conducted an anti-malaria campaign in which they educated adult village residents on malaria through song, drama, and poetry recitals. This study reported an increase in knowledge of malaria prevention among participants at post-intervention.

The pilot study described in this article tested the use of a culturally tailored theatrical performance delivered by preschool children to relay BCS recommendations. We hypothesized the performance would increase Chinese 
American women's knowledge of BCS guidelines.

\section{Theoretical/Conceptual Framework}

This intervention was guided by components of Diffusion of Innovation Theory. The two components of the Diffusion of Innovation Theory (Rogers, 1995) were characteristics of potential adopters (Chinese American women) and change agents (preschool children of these Chinese American women). In this pilot study, the likelihood that children can be change agents to deliver messages was measured by participants' BCS knowledge change. Knowledge is an important factor in theoretical models guiding BCS efforts (Curry \& Emmons, 1994), including the widely-used Health Belief Model (Ersin \& Bahar, 2011).

\section{Methods}

\section{Design}

The study utilized a single group pre- and postintervention design to examine using preschoolers' performance in changing knowledge of the BCS guidelines from the Komen Breast Cancer Foundation [Komen; (Susan G. Komen Breast Cancer Foundation, 2005) ]. The study used Komen's guidelines because Komen is a recognized international advocate for breast cancer control. In 2005, a community-based health organization, (CBO) in collaboration with San Francisco preschools, conducted theatrical performances to raise awareness of BCS guidelines among Chinese American women. Four preschools were selected because of its student majority from Chinese American families. Institutional Review Board approval of the study was obtained from the CBO's affiliated hospital. The 20-minute performance consisted of three segments: (a) holding signage in Chinese and English with individual BCS guidelines; (b) singing a popular Chinese children's song, "Mommy Is the Best Person in the World," while holding the signage; and (c) saying in English and Chinese, "Mommy, Grandma, and aunties, we love you. Please take good care of yourself." Over $90 \%$ of the preschoolers were from Chinese immigrant families. The team worked with teachers to coach the preschoolers before the performance, and consulted with local clinicians specializing in childhood development to ensure that preschoolers could carry out the performance and convey messages in segment (c), described above, to adults. Parents provided permission for their children to perform. Inclusion criteria included: Chinese American female audience member, ages 18 and older, and able to read English or Chinese.

\section{Sample}

Study participants were recruited among female adult audience members who attended theatrical performances at four preschools in San Francisco. Sample inclusion criteria were: Chinese American female audience member; ages 18 and older; and able to read English or Chinese. Preschools were selected due to its majority of students from Chinese immigrant families.

\section{Measures}

Eligible participants who provided informed consent completed self-administered paper surveys in their preferred language before and after the performance. At pre-test, participants' knowledge of Komen's 2005 BCS guidelines (Susan G. Komen Breast Cancer Foundation, 2005) were assessed by endorsing the correct guidelines from a list of three true and three false BCS guidelines. Participants could select multiple answers. At post-test, in addition to assessing knowledge, participants' perceived attentiveness to the performance was measured by a single item, in which they compared their attentiveness to messages delivered through the performance versus conventional venues. Participants indicated their relationship to child performers. Demographic information was obtained at post-test. Questionnaires were focus-group tested with 8 participants from the target population for readability and cultural appropriateness.

\section{Analysis}

Data were analyzed using SAS 9.2. A score measuring participants' BCS knowledge was created by summing the number of correct guidelines that participants endorsed in pre- and post-tests. The scores ranged from 0 (none) to 3 
(all 3 guidelines were endorsed). The Wilcoxon signed-rank test was used to assess differences in pre- and post-tests. McNemar's chi-square test was used to compare changes in proportions for endorsing each listed true or false guideline from pre- to post-test. Because of multiple comparisons, alpha of 0.01 was used as the significance level. Linear regression was used to estimate associations between participant characteristics and knowledge score changes. Construct validity was tested by Kendall's tau correlation coefficient between the ordinal education variable and the number of true guidelines endorsed at pre-test.

\section{Results}

There were 194 eligible women and 90\% $(\mathrm{N}=177)$ consented to participate and completed both surveys. Participants were ages 25 to 77 (mean age $=40.1, \mathrm{SD}=11.7$ ), of which $29 \%$ were aged 40 and older. As a conservative

Table 1

\section{Participants' Characteristics ( $\mathrm{N}=\mathbf{1 7 7})$}

\begin{tabular}{lrr}
\hline Demographics & $\mathrm{n}$ & $\%$ \\
\hline Birth country & & \\
United States & 27 & 15.6 \\
Hong Kong, Macau, Taiwan & 31 & 17.9 \\
China & 93 & 53.8 \\
Others & 22 & 12.7 \\
Marital status & & \\
Single & 5 & 2.9 \\
Married & 166 & 96.0 \\
Divorced & 0 & 0.0 \\
Widowed & 2 & 1.2 \\
Education & & \\
Less than high school & 40 & 23.4 \\
High school & 50 & 29.2 \\
College degree & 81 & 47.4 \\
Annual household income & & \\
Less than \$30,000 & 76 & 45.5 \\
\$30,000 - \$50,000 & 22 & 13.2 \\
\$50,001 - \$80,000 & 16 & 9.6 \\
More than \$80,000 & 53 & 31.7 \\
Mother has health insurance & 117 & 66.1 \\
In U.S. for 10+ years & & \\
In United States longer than 10.1 \\
years & 61 & 36.1 \\
\hline & & \\
& & \\
\hline
\end{tabular}

estimation, missing data on BCS knowledge was included in the analysis and considered as “don't know".

Table 1 illustrates participant characteristics and Table 2 shows participants' endorsement of BCS guidelines before and after the performance. The mean number of true guidelines endorsed increased from 1.17 (SD $=0.88)$ to 1.78 (SD =1.01), which indicated that respondents averaged a 0.61 (SD $=0.13$ ) increase in the number of correct guidelines endorsed to the six items measured at post-test. This difference was significant $(\mathrm{p}<0.01)$ according to Wilcoxon signed-rank test results. For individual knowledge items, significant knowledge changes were observed on BCS guidelines related to breast self- exam (BSE; Q1 \& 2), mammogram (Q4) and clinical breast exam (CBE; Q5). For BSE, the proportion who endorsed the false guideline (Q1) decreased from $35.6 \%$ to $18.6 \%$ $(\mathrm{p}<0.01)$. Conversely, the proportion endorsing the true guideline (Q2) increased from $23.2 \%$ to $59.3 \%(\mathrm{p}<0.01)$ after the performance. For mammogram (Q4), the endorsement of the true guideline increased from $49.7 \%$ to $61.6 \%$ ( $\mathrm{p}<$ 0.01). For CBE, the endorsement of the true guideline (Q5) increased from $44.1 \%$ to $56.5 \%$ $(p<0.01)$. No significant changes were observed for false guidelines on mammogram (Q3) and CBE (Q6). For construct validity, the association between participants' educational level and true guideline endorsement was significant but weak $(\tau=0.15, \mathrm{p}=0.03)$.

At post-test, a majority (78.7\%) of the participants reported that they were more attentive to the message when it was delivered by the performance compared to other conventional venues, with $46.2 \%$ "much more attentive," 32.5\% "slightly more attentive," 18.3\% "same," and 3.0\% "much less attentive." Regression analysis revealed that US born participants had significantly higher gain of correct BCS guidelines endorsements compared to their non-US born counterparts $(\beta=0.49$, SE $\left.\mathrm{B}=0.23, \mathrm{R}^{2}=0.03\right)$. No association was observed between knowledge gain and length of residency, other demographic variables, and performance attentiveness. 
Sun A.C., Kessell E.R., Tsoh J.Y., Chan J., Chang J. / Californian Journal of Health Promotion 2013, Volume 11, Issue 3, Pages 74-

Table 2

\begin{tabular}{|c|c|c|c|c|}
\hline Questionnaire item & $\begin{array}{r}\text { Pre-test } \\
\%(n)\end{array}$ & $\begin{array}{r}\text { Post-test } \\
\%(n)\end{array}$ & $\begin{array}{l}\text { Change from } \\
\text { Pre-test \% (n) }\end{array}$ & p-value* \\
\hline FALSE GUIDELINES & & & & \\
\hline Q1: Breast Self Exam & $35.6 \%(63)$ & $18.6 \%(33)$ & $-16.9 \%(30)$ & $<0.01$ \\
\hline Q3: Mammogram & $20.9 \%(37)$ & $14.7 \%(26)$ & $-6.2 \%(11)$ & 0.05 \\
\hline $\begin{array}{l}\text { Q6: Clinical Breast Exam } \\
\text { TRUE GUIDELINES }\end{array}$ & $22.6 \%(40)$ & $15.8 \%(28)$ & $-6.8 \%(12)$ & 0.08 \\
\hline Q2: Breast Self Exam & $23.2 \%(41)$ & $59.3 \%(105)$ & $+36.2 \%(64)$ & $<0.01$ \\
\hline Q4: Mammogram & $49.7 \%(88)$ & 61.6\% (109) & $+11.9 \%(21)$ & $<0.01$ \\
\hline Q5: Clinical Breast Exam & $44.1 \%(78)$ & $56.5 \%(100)$ & $+12.4 \%(22)$ & $<0.01$ \\
\hline
\end{tabular}

*McNemar's chi-square test

\section{Discussion}

While current BCS guidelines have changed since the time of the study, findings from this pilot study suggested that Chinese American women's knowledge of BCS guidelines increased after watching a culturally-tailored preschool theatrical performance. Although this study did not investigate post-performance behavioral changes related to BCS, investigators suggest that knowledge is one of the first steps toward behavior change (Marx, et al., 2008). Other factors, including cultural and linguistic barriers, influence BCS knowledge among Chinese immigrant women (Chen, 2013; Ma, et al., 2012). These factors are reflected in our finding that U.S.-born participants had significant higher knowledge gain of BCS guidelines after the performance compared to the foreign born participants. Differences in cultural views of disease prevention and English proficiency may explain this finding (Chen, 2013; Liang, et al., 2009). In the Chinese community, culturally-tailored and in-language theatrical performances involving preschoolers often occur at preschool graduations and community events, but have not been used to deliver health messages. Family members, including grandparents and aunts, usually attend preschool performances. At these performances, children sing and dance to popular Chinese folk songs, such as "Mommy is the Best in the World". Therefore, performances involving children as change agents may be an excellent opportunity and cultural environment to deliver health messages to parents and relatives. Our findings suggested this venue was appropriate. Over $78 \%$ of participants indicated being anywhere from slightly to much more attentive to the message delivered by this venue compared to conventional methods.

To the authors' knowledge, there are no published studies on promoting BCS guidelines to Chinese Americans involving preschoolers. This preliminary data warrants further empirical investigations in larger randomized controlled trials examining all components of Diffusion of Innovation Theory.

\section{Limitations}

There were several limitations. The study lacked a comparison group and data were collected from a convenience sample of Chinese American women. Thus, study results may not be generalizable to other populations of women. Answers were self-reported and the order of response options to BCS guidelines in pre- and post-tests may have generated response bias. Because the questionnaire items were grouped by categories of BSE, CBE, and mammography, good test-takers could answer correctly through process of elimination. Despite these limitations, this pilot study's findings suggested that interventions involving young children as change agents to deliver simple health messages such as BCS guidelines are feasible and promising to promote knowledge and potential desired behavioral change, regardless of participants' ages, socioeconomic status, and relationship to child performers. 


\section{Acknowledgments}

This work was supported by grants from Susan G. Komen for the Cure, San Francisco Chapter, and the Chinese Community Health Resource Center (CCHRC). The authors also would like to thank the following CCHRC staff and interns for their assistance in material translation, data collection and manuscript formatting and editing: Yvonne Liang, Cecilia Pang, Sarah Stearman, Joyce Cheng, Siwen Shen, and Katie Zhao.

\section{References}

American Cancer Society. (2011). Breast Cancer Facts and Figures 2011 - 2012. (No. 861011). Atlanta, GA: American Cancer Society.

Ayi, I., Nonaka, D., Adjovu, J. K., Hanafusa, S., Jimba, M., Bosompem, K. M., et al. (2010). Schoolbased participatory health education for malaria control in Ghana: engaging children as health messengers. Malaria Journal, 9, 98.

Chen, W. T. (2013). Chinese female immigrants english-speaking ability and breast and cervical cancer early detection practices in the new york metropolitan area. Asian Pacific Journal of Cancer Prevention, 14(2), 733-738.

Curry, S. J., \& Emmons, K. M. (1994). Theoretical models for predicting and improving compliance with breast cancer screening. Annals of Behavioral Medicine, 16(4), 302-316.

Ersin, F., \& Bahar, Z. (2011). Effect of health belief model and health promotion model on breast cancer early diagnosis behavior: a systematic review. Asian Pacific Journal of Cancer Prevention, 12(10), 2555-2562.

Liang, W., Wang, J., Chen, M. Y., Feng, S., Yi, B., \& Mandelblatt, J. S. (2009). Cultural views, language ability, and mammography use in Chinese American women. Health Education \& Behavior, 36(6), 1012-1025.

Ma, G. X., Gao, W., Lee, S., Wang, M., Tan, Y., \& Shive, S. E. (2012). Health seeking behavioral analysis associated with breast cancer screening among Asian American women. International Journal of Women's Health, 4, 235-243.

Marx, J. J., Nedelmann, M., Haertle, B., Dieterich, M., \& Eicke, B. M. (2008). An educational multimedia campaign has differential effects on public stroke knowledge and care-seeking behavior. Journal of Neurology, 255(3), 378-384.

Rogers, E. (1995). Diffusion of Innovation (4th ed.). New York: Free Press.

Susan G. Komen Breast Cancer Foundation. Healthy Behaviors, 2005. Available at: http://ww5.komen.org. Accessed March 4, 2005. 
Author Information

*Angela C. Sun, PhD, MPH

Joanne Chan, BA

Joyce Chang

Chinese Community Health Resource Center

845 Jackson Street, Suite 101

San Francisco, CA, 94133

Email: angelas@chasf.org; joannec@chasf.org;

jychang05@comcast.net

Phone: 650-438-0491

Fax: 415-963-3411

Eric R. Kessell, PhD, MPH

UCSF School of Medicine

Division of Hospital Medicine-SFGH

Box 1364

San Francisco, CA 94143-1364

Email: EKessell@medsfgh.ucsf.edu

Phone: 415-206-4921

Fax: 415-206-4948

Janice Y. Tsoh, PhD

University of California, San Francisco

Department of Psychiatry

401 Parnassus Ave (0984-TRC)

San Francisco, CA 94143

Email: JTsoh@lppi.ucsf.edu

Phone: 415-502-8438

Fax: 415-476-7734

* corresponding author 